www.jmscr.igmpublication.org

Impact Factor 5.244

Index Copernicus Value: 83.27

ISSN (e)-2347-176x ISSN (p) 2455-0450

crossref DOI: _https://dx.doi.org/10.18535/jmscr/v4i11.106

\title{
Basaloid Cloacogenic Carcinoma of Anal Canal Showing Complete Response to Chemoradiotherapy: A Rare Case with Review of Literature
}

\author{
Authors \\ Kaushal Deep Singh*, Farheen Shahma** \\ *Senior Resident, **Undergraduate Student
}

Department of Surgery, Jawaharlal Nehru Medical College, Aligarh Muslim University, Aligarh

\begin{abstract}
Cloacogenic carcinoma is a rare tumor originating from epithelium of the anal transition zone of embryonic residuals. It accounts for only 2\%-3\% of all neoplasm arising in the anorectal canal and has clinical and morphological characteristics that distinguish them from the ordinary varieties of adenocarcinoma and squamous cell carcinoma of the anorectum. We report here a case of a middle aged male who presented to us with history of altered bowel habits, pain during defecation, passage of fresh blood in stools and pruritus in anal region and on examination there was an ulcerative growth in the anal canal. The diagnosis of basaloid variety of cloacogenic carcinoma was made upon biopsy and histopathological examination. Patient was put on chemoradiation and responded well with complete disappearance of growth macroscopically and clinically but was then lost in follow-up.Owing to the paucity of published literature on this rare malignant tumor this case is being reported here.
\end{abstract}

Key Words: Cloacogenic carcinoma, basaloid, anal canal, chemoradiation, complete resolution.

\section{Introduction}

Cloacogenic carcinoma (CC) is a rare tumor that has origin from the embryonic residuals of anal transitional zone. The morphological characteristics of CC differentiate it from the other ordinary varieties of squamous cell carcinomaand adenocarcinoma of the anorectum ${ }^{(1)}$. Histological classification is based on predominance of basaloid features with or without elements of squamous differentiation (such as epithelial pearls and individual cell keratinization) or glandular features (such as acinar arrangements and mucin formation $)^{(2)}$. Histological and ultrastructural studies have indicated that these neoplasms may arise from transitional cloacogenic epithelium lining the anal ducts or from the basal layer of anal squamous epithelium ${ }^{(3)}$. Outside the anal canal, it has been postulated that these tumors arise from cloacogenic embryologic remnants, squamous metaplastic epithelium, or totipotential basal cells ${ }^{(4)}$. Radical surgery in the form of abdominoperineal resection followed by chemoradiation is considered optimal treatment for this condition. Only few such cases exclusively involving the anal canal are reported in the literature $^{(5)}$. We report here a case of a middle aged male who presented to us with a growth protruding from the anus.

\section{Case Report}

A 52 years' male presented to us with 6-months history of constipation and pain in defecation. 
Patient also had itching in perianal area and passage of fresh blood per rectum with stools for 3 months. Patient had noticed a small protrusion at the anal opening during itching for which he consulted a local practitioner who diagnosed him to be suffering from hemorrhoids and treated him with 3 sittings of injection sclerotherapy 3-4 weeks apart. However, the patient was not relieved and presented to us with these complaints. There was no history of abdominal pain or pain in any other part of the body, jaundice, nausea or vomiting or melena. He had neither a relevant past history nor any contributory family history. On examination of perianal area, there was an ulcerative circumferential growth protruding from the anal opening (Figure 1) which was extending about $1 \mathrm{~cm}$ into the anal canal. Perabdominal examination was within normal limit. A biopsy was taken from the growth and sent for histopathological examination which showed basaloid cells with hyperchromatic nuclei and scanty cytoplasm arranged in solid sheets with peripheral palisading and focal clusters of squamous differentiation suggestive of basaloid type of cloacogenic carcinoma (Figure 2). Serum carcinoembryonic antigen (CEA) was 1.2 $\mu \mathrm{L} / \mathrm{L}$ and serum alpha-fetoprotein (AFP) was 0.8 U/L. A contrast-enhanced computed tomography (CECT) of the patient was done which showed a growth upto $1.2 \mathrm{~cm}$ into the anal canal involving the mucosa and sub-mucosa (Figure 3) but there was no other organ involvement or local lymph node involvement. Patient was planned for a colostomy followed by neoadjuvant chemoradiotherapy (CRT) followed by definitive surgery. However, patient did not give consent for surgery but was ready for CRT. Patient was put on neoadjuvant chemotherapy (NACT) which was planned as 5-Fluorouracil (5-FU) $500 \mathrm{mg} / \mathrm{m}^{2}$ body surface area (BSA) Day 1-3 with cisplatin $50 \mathrm{mg} / \mathrm{m}^{2}$ BSA Day 1 for 2 cycles at 3-week interval. NACT was followed 3-weeks later by CRT in the form of external beam radiotherapy, total dose 45 Gray divided into 5 fractions for 5 weeks with Inj. Mitomycin-C $15 \mathrm{mg} / \mathrm{m}^{2}$ on Day-1 and Inj. 5-
FU $750 \mathrm{mg} / \mathrm{m}^{2}$ on Day 1-5 and Day 29-33. At 3-months post-CRT, there was no macroscopic growth on inspection and on digital rectal examination (Figure 4); in CECT abdomen (Figure 4); and on lower gastrointestinal endoscopy. Patient is on monthly follow-up for last 1 year without any recurrence.

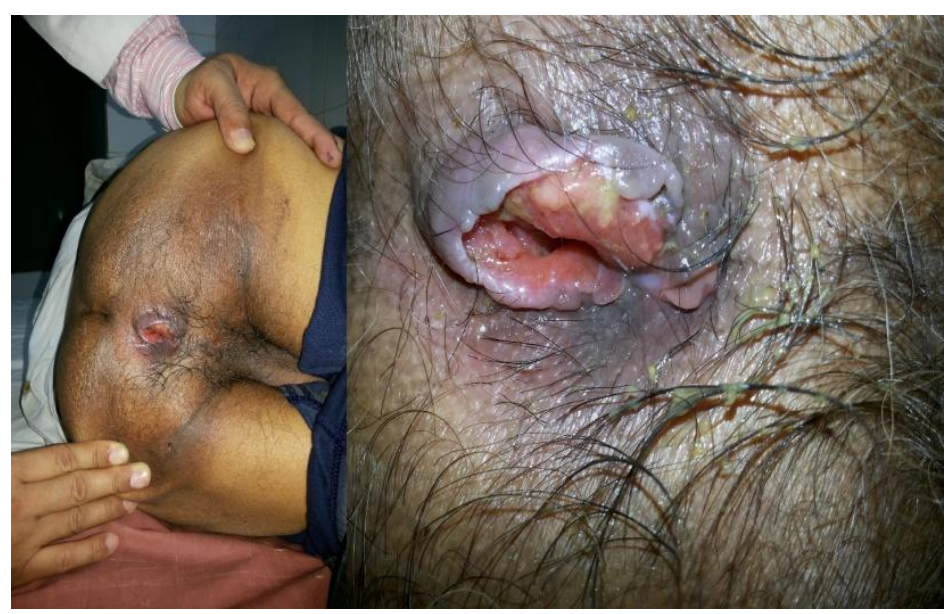

Figure 1: Clinical photograph showing ulcerative circumferential growth protruding from the anal opening extending about $1 \mathrm{~cm}$ into the anal canal

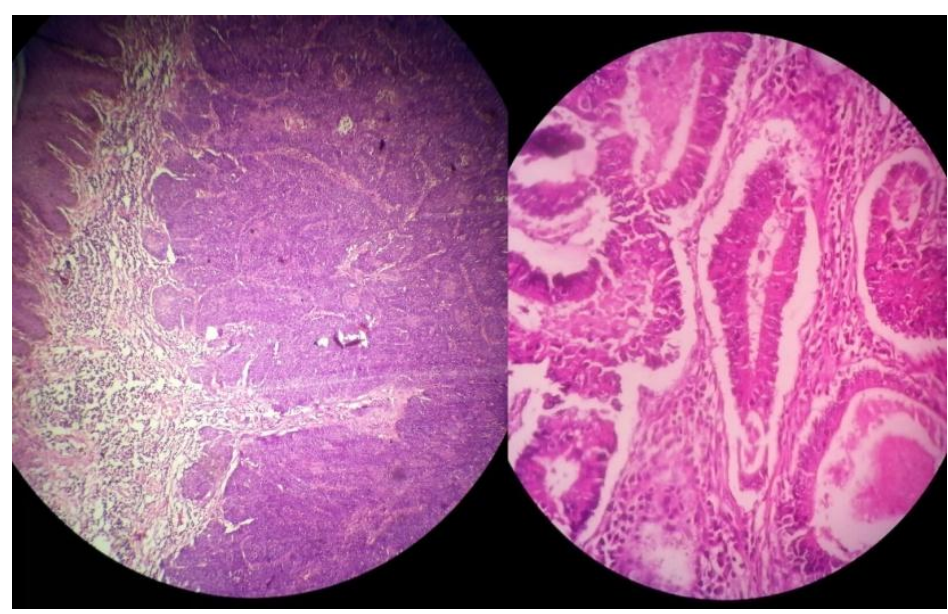

Figure 2: Microscopic appearance (400X) of tumor showing basaloid cells with hyperchromatic nuclei and scanty cytoplasm arranged in solid sheets with peripheral palisading and focal clusters of squamous differentiation. 


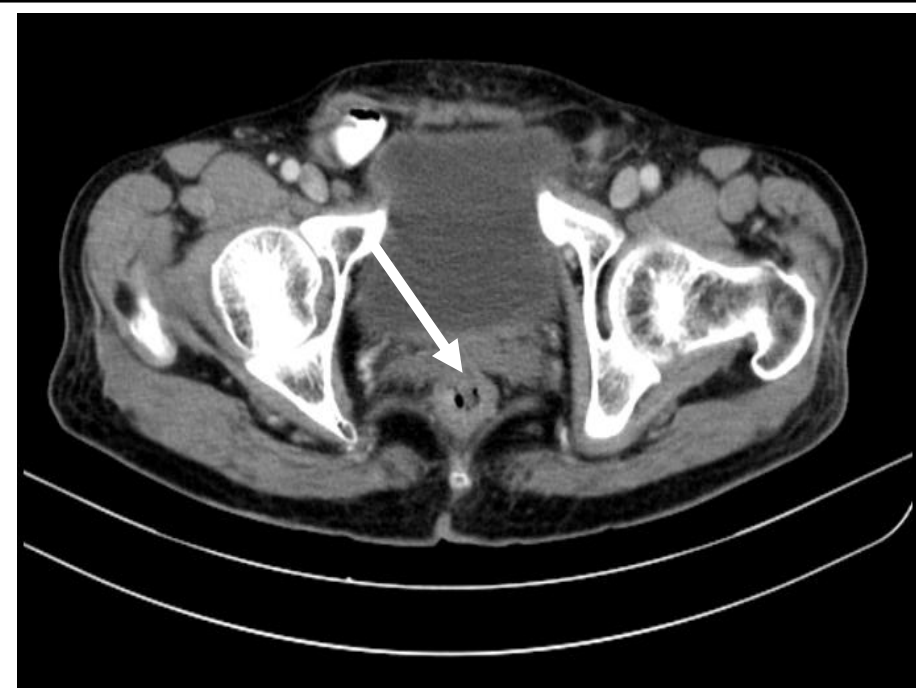

Figure 3: CECT showing the growth involving the anal region. Growth up to $2.2 \mathrm{~cm}$ into the anal canal involving the mucosa and sub-mucosa but no organ or local lymph node involvement (T2N0M0; Stage II)

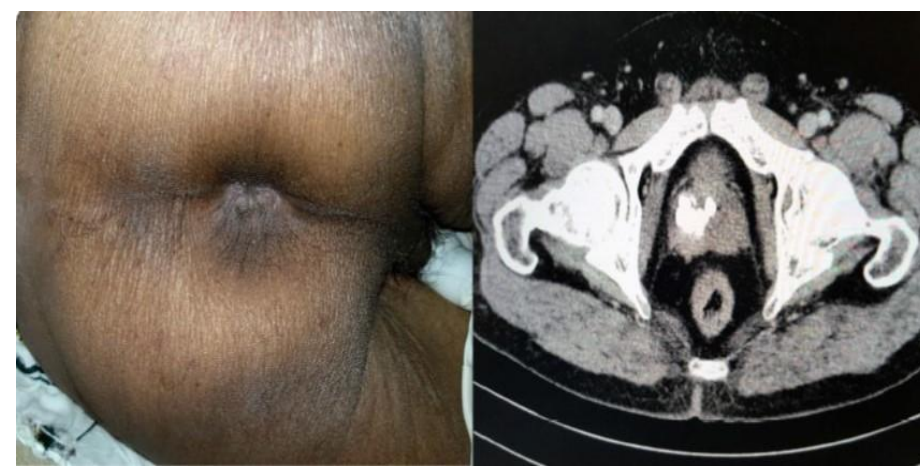

Figure 4: Absence of any protruding growth from anus at 3-months post-CRT and CECT shows absence of any growth in anal region at 6 month post-CRT

\section{Discussion}

Cloacogenic carcinoma is a rare neoplasm of the anal canal and rectum. It accounts for only $2 \%-$ $3 \%$ of all neoplasm arising in the anorectal region $^{(2)}$. Outside the anal canal, it has been postulated that these tumors arise from cloacogenic embryologic remnants, squamous metaplastic epithelium, or totipotential basal cells $^{(4)}$. The mucosa of the anal transitional zone has an appearance that is intermediate between non-keratinizing squamous and columnar epithelium, and can contain several cell types in varying proportions: basaloid, columnar, cuboidal, transitional (urothelium-like), and cells $^{(2)}$. Cloacogenic carcinoma expresses cytokeratin polypeptides similar to those of the basal layer of anal squamous epithelium, of the anal transitional zone epithelium and of a layer of basal cells in the anal glands ${ }^{(6)}$. Thus each of the above cell types may be the cell of origin of cloacogenic carcinoma. The "transitional" variant is composed of cells similar to the intermediate zone cells of anal transitional epithelium, an observation confirming the concept that the transitional form of cloacogenic carcinoma is derived from the anal transitional zone. The "basaloid" and pleomorphic variants appear to represent less differentiated forms of cloacogenic carcinoma $^{(3)}$. The morphologic patterns that are commonly associated with basaloid cloacogenic carcinoma include nested and trabecular growth of small cells without the intercellular bridges typical of conventional squamous cell carcinoma, although foci of more conventional squamous differentiation can usually be found. Peripheral palisading similar to that of cutaneous basal cell carcinoma may be present. Sometimes, these tumors can have small cystic foci lined by mucinproducing cells, the reason for the former designation of mucoepidermoid carcinoma. Others may grow in lobules and contain prominent eosinophilic, hyaline, pauci-cellular basement membrane-like material around and within tumor nests, resulting in an appearance simulating that of an adenoid cystic carcinoma. Central necrosis and mitotic figures may be prominent, but cellular pleomorphism is not typical ${ }^{(7)}$. Serota $e t a l^{(2)}$ in their retrospective study of 35 patients with anal cloacogenic carcinomas showed that the histological characteristics of the tumors were correlated with their biological behavior. The basaloid squamous type of cloacogenic carcinoma was more common in women (3.6:1) and had a more favorable course in both men and women with a mean survival of 5.0 years. Olafinlade et $a l^{(1)}$ analyzed the clinic-pathologic characteristics, treatment and survival of cloacogenic and squamous cell carcinoma of the anus using a 15-year experience; they found cloacogenic and squamous 
cell carcinoma to account for $2.5 \%$ of the large bowel cancers, the male-to-female ratio was $1: 1.5$ in those with cloacogenic cancer and 1.8:1 in those with squamous carcinoma. The mean age of presentation was $57 \pm 2.8$ years for squamous cell carcinoma cases and 66.3 \pm 3.4 years in those with cloacogenic carcinoma. Han et $a l^{(8)}$ in their review found basaloid adenocarcinomas in 16 cases, transitional cell adenocarcinoma in 12, and no recorded histopathological type in the other 18. Male-tofemale ratio in their study was 1.1:1, with female preference, and the mean age was 47.0 years. Besides the anorectum, other sites have been described including the vagina, urethra, sigmoid colon, splenic flexure, descending colon, vulva and perianal $\operatorname{skin}^{(4,9)}$. Several etiologic associations have been described, such as chronic fistula-in-ano, anal Crohn's disease, and anal sexual intercourse, raising the issue of cancer prevention and early detection ${ }^{(8)}$. The most common clinical presentation is rectal bleeding, pain in defecation, constant discomfort in anal region, pruritus, constipation and presence of an anal mass ${ }^{(2,8)}$. The digital rectal examination and lower gastrointestinal endoscopy can assess the primary size and degree of fixation of these tumors. Endosonography has been shown to give accurate information about size and depth of invasion and possible perirectal lymph node involvement tool for staging and follow-up of these patients $^{(1)}$. CECT and endorectal-coil magnetic resonance imaging (MRI) also give relevant information regarding extent of tumor and its spread.

Nigro et $a l^{(10)}$ reported that chemotherapy and radiation for anal cloacogenic carcinoma was better than aggressive surgery. Indinnimeo et $a l^{(11)}$ performed APR followed by adjuvant CRT in rectal CC. Fayazet $a l^{(12)}$ reported a case of CC of anal canal with extensive liver metastasis which showed complete remission with 5-FU and cis-dichlorodiammineplatinu (CDDP) chemotherapy only and remained disease free five \& half years after therapy. In the cases reported by Han et al(8), both patients had rectal CC. APR was performed in both. One patient received CRT and died after 2.5 years and other received 5-FU based chemotherapy and was disease free even after 5 years. Bertani et $a l^{(13)}$ retrospectively investigated the treatment of cloacogenic cancers during an 8-year period. The medical records of 7 patients affected by cloacogenic carcinoma were analyzed. Three patients presented distant metastases at the time of diagnosis. CRT using 5-FU with mitomycin or cisplatin was considered the gold standard for those cases amenable to cure. After a mean follow-up time of 33 months (range 9-100), disease recurrence or progression was observed in 6 patients, which caused death in 3 of them. 3- and 5 -year actuarial overall survival rates were $71 \%$ and $48 \%$, respectively. They suggested that the cloacogenic origin could present prognostic relevance within the wide spectrum of anal cancers. This study demonstrated the possible promising role of CRT in anorectal CC. Serota $e t a l^{(2)}$ in their retrospective study of 35 patients with anal cloacogenic carcinomas showed that it had a more favorable course in both men and women, with a mean survival of 5.0 years. Glandular variants of these tumors, with an adenocystic or mucoepidermoid pattern, occurred predominantly in men and had a more aggressive course, manifested by early metastases to inguinal and mesenteric lymph nodes, liver, and lung, with mean survival limited to 2.5 years. Nine of the 11 patients who survived longer than five years had the basaloid squamous histological pattern and were treated by abdominoperineal resection (APR) or pelvic exenteration; five of these patients also received postoperative therapy with radiation. The overall actual five-year survival for patients with anal cloacogenic carcinoma was $41 \%$ in this study. The histological pattern of anal cloacogenic carcinoma provides useful prognostic information to the clinician. In the review by Han et $a l^{(8)}$, among the 38 patients with cloacogenic carcinoma of anal canal, which had records of treatment, 29 underwent surgical procedure, 5 underwent radiotherapy only, and 4 
no-treatment, and the other 8 had no record of treatment. All the patients who underwent resection received adjuvant chemotherapy and/or radiotherapy post-operatively. The surgical procedure was APR in 24 patients, and palliative resection in 5 . They also found that of the 39 cases of cloacogenic carcinoma of anal canal who had follow-up data, the overall 2 and 5-year survival rates were $69.2 \%$ and $43.6 \%$, respectively. When the carcinoma involves the regional lymph nodes, or there is evidence of an anaplastic pattern histologically, a poorer prognosis can be expected ${ }^{(14)}$. Inguinal node dissection is indicated, if the nodes appear clinically involved. Inflammatory cutaneous metastasis has also been reported in CC and carry poor prognosis due to absence of response to chemoradiation $^{(15)}$. Salmon et al ${ }^{(16)}$ showed that the 5 -year survival was better in cloacogenic carcinoma $(62 \%)$ than in squamous cancer $(56 \%)$. However, Olofinlade et $a l^{(1)}$ reported that the overall 5-year survival was similar for both cloacogenic and squamous cell carcinoma.

\section{Conclusion}

Anorectal cloacogenic carcinoma has overall poor outcome due to the morbidity associated with APR and CRT. However, patients with only anal canal involvement, though rare, may respond well to CRT like our patient. Hence in such patients, a more conservative approach to surgery following CRT seems feasible; though long term studies involving large cohort of patients is required to arrive at a firm conclusion.

\section{References}

1. Olofinlade O, Adeonigbagbe O, Gualtieri N, Gingold B, Berlin I, Sayeed R, et al. Anal carcinoma: a 15-year retrospective analysis. Scandinavian journal of gastroenterology. 2000;35(11):1194-9.

2. Serota AI, Weil M, Williams RA, Wollman JS, Wilson SE. Anal cloacogenic carcinoma: Classification and clinical behavior. Archives of Surgery. 1981;116(4):456-9.
3. Gillespie JJ, MacKay B. Histogenesis of cloacogenic carcinoma. Fine structure of anal transitional epithelium and cloacogenic carcinoma. Human pathology. 1978;9(5):579-87.

4. Akbulut S. What is the clinicopathological characteristic of cloacogenic carcinoma outside the anorectal zone? Hepatogastroenterology. 2011;58(105):52-5.

5. Naito $Y$, Hotta $T$, Yamamoto H, Iwamoto $\mathrm{K}$, Murakami S, Tomimatu J, et al. A case of cloacogenic carcinoma originated from anal gland, presented as a rectal submucosal mass. Nippon Shokakibyo Gakkai Zasshi. 1988;85(2):281-6.

6. Levy R, Czernobilsky B, Geiger B. Cytokeratin polypeptide expression in a cloacogenic carcinoma and in the normal anal canal epithelium.

7. Shia J. An update on tumors of the anal canal. Archives of pathology \& laboratory medicine. 2010;134(11):1601-11.

8. Han S, Ji S, Guo S, Li W. Cloacogenic carcinoma of anal canal: two case reports and review of Chinese literature. Chin Ger J ClinOncol. 2010;9(5):302-4.

9. Dujovny N, Quiros RM, Saclarides TJ. Anorectal anatomy and embryology. Surgical oncology clinics of North America. 2004;13(2):277-93.

10. Nigro ND. An evaluation of combined therapy for squamous cell cancer of the anal canal. Dis Colon Rectum. 1984;27(12):763-6.

11. Indinnimeo M, Cicchini C, Stazi A, Limiti MR, Ghini C. An unusual location of cloacogenic carcinoma. International surgery. 1998;83(4):343-6.

12. Fayaz S, Vasishta S, Motawy M. Case report of long term survivor of metastatic cloacogenic carcinoma of the anal canal with chemotherapy. The Gulf journal of oncology. 2007(2):65-8.

13. Bertani E, Chiappa A, Mazzarol G, Contino G, Lazzari R, Zampino MG, et al. 
Aggressive Treatment Approach for Cloacogenic Carcinoma of the Anorectum: Report from a Single Cancer Center. Digestive surgery. 2010;27(4):297-301.

14. Shindo K, Bacon H. Transitional-cell cloacogenic carcinoma of the perianal region, anal canal, and rectum. Dis Colon Rectum. 1971;14(3):222-5.

15. Peppe H, Bianchi C, Bianchi O, Stringa S. [Cutaneous metastasis of a cloacogenic tumor]. Medicinacutaneaibero-latinoamericana. 1987;15(4):293-7.

16. Salmon RJ, Zafrani B, Labib A, Asselain B, Girodet J. Prognosis of cloacogenic and squamous cancers of the anal canal. Dis Colon Rectum. 1986;29(5):336-40.

How to cite this article: Singh KD, Shahma F. Basaloid Cloacogenic Carcinoma of Anal Canal Showing Complete Response to Chemoradiotherapy: A Rare Case with Review of Literature. J Med Sci Clin Res. 2016;4(11):14168-73. 